\title{
Neighborhood smoking norms modify the relation between collective efficacy and smoking behavior
}

\author{
Jennifer Ahern ${ }^{\mathrm{a}, \mathrm{b}, \mathrm{c}, *}$, Sandro Galea ${ }^{\mathrm{b}, \mathrm{c}, \mathrm{d}}$, Alan Hubbard ${ }^{\mathrm{e}}, \mathrm{S}$. Leonard Syme ${ }^{\mathrm{a}}$ \\ a Division of Epidemiology, University of California, Berkeley School of Public Health, 101 Haviland Hall, Berkeley, CA 94720, USA \\ ${ }^{\mathrm{b}}$ Department of Epidemiology, University of Michigan School of Public Health, 109 Observatory Street, Ann Arbor, MI 48109, USA \\ ' Center for Urban Epidemiologic Studies, New York Academy of Medicine, 1216 5th Avenue, New York, NY 10029, USA \\ d Department of Epidemiology, Columbia University Mailman School of Public Health, 622 168th Street, New York, NY 10032, USA \\ e Division of Biostatistics, University of California, Berkeley School of Public Health, 101 Haviland Hall, Berkeley, CA 94720, USA
}

\section{A R T I C L E I N F O}

\section{Article history:}

Received 15 February 2008

Received in revised form

19 September 2008

Accepted 29 September 2008

Available online 17 November 2008

\section{Keywords:}

Neighborhood

Social cohesion

Informal social control

Norms

Smoking

Cigarettes

\begin{abstract}
A B S T R A C T
Background: Although neighborhoods with more collective efficacy have better health in general, recent work suggests that social norms and collective efficacy may in combination influence health behaviors such as smoking.

Methods: Using data from the New York Social Environment Study (conducted in 2005; $n=4000$ ), we examined the separate and combined associations of neighborhood collective efficacy and anti-smoking norms with individual smoking. The outcome was current smoking, assessed using the World Mental Health Comprehensive International Diagnostic Interview (WMH-CIDI) tobacco module. Exposures of interest were neighborhood collective efficacy, measured as the average neighborhood response on a wellestablished scale, and neighborhood anti-smoking norms, measured as the proportion of residents who believed regular smoking was unacceptable. All analyses adjusted for demographic and socioeconomic characteristics, as well as history of smoking prior to residence in the current neighborhood, individual perception of smoking level in the neighborhood, individual perception of collective efficacy, and individual smoking norms.

Results: In separate generalized estimating equation logistic regression models, neighborhood collective efficacy was not associated with smoking (OR 1.06, 95\% CI 0.84-1.34) but permissive neighborhood smoking norms were associated with more smoking (OR 1.34, 95\% CI 1.03-1.74), particularly among residents with no prior history of smoking (OR $2.88,95 \%$ CI 1.92-4.30). When considered in combination, where smoking norms were permissive, higher collective efficacy was associated with more smoking; in contrast, where norms were strongly anti-smoking, higher collective efficacy was associated with less smoking. Conclusions: Features of the neighborhood social environment may need to be considered in combinations to understand their role in shaping health and health behavior.
\end{abstract}

(c) 2008 Elsevier Ireland Ltd. All rights reserved.

\section{Introduction}

Research in a variety of disciplines including sociology, criminology, and psychology has suggested that cohesiveness and collective power of societies and communities are associated with improved health and wellbeing (Bandura, 2001; Durkheim, 1897; Faris and Dunham, 1939; Shaw and McKay, 1942). In this vein, Bandura introduced the notion of collective agency which he termed "collective efficacy" (Bandura, 2001). This concept combines notions of the cohesiveness of a group (social cohesion), with ideas about their

\footnotetext{
* Corresponding author at: School of Public Health, University of California, Berkeley, 101 Haviland Hall, Berkeley, CA 94720-7358, USA. Tel.: +1 510643 4350; fax: +1 5106435163 .

E-mail address: jahern@berkeley.edu (J. Ahern).
}

potential efficacy in achieving group goals (informal social control) (Sampson et al., 1997).

In epidemiologic analyses, the presence of collective efficacy in a neighborhood has typically been associated with better health and fewer social ills (Kawachi and Berkman, 2000; Lomas, 1998; Sampson et al., 1997). However, recent discussions suggest that social cohesion, informal social control, and other related constructs may not be unequivocally beneficial (Greiner et al., 2004; Kushner and Sterk, 2005; Portes, 1998). Portes suggests that where social cohesion is high, there is the potential for unhealthy behavioral norms to be enforced on residents (Portes, 1998). Thus, when examining neighborhood cohesion in relation to health behavior, it may be important to consider the norms of the neighborhood in conjunction with the cohesiveness of a neighborhood to understand how the social environment will shape behavior (Durkheim, 1897; Kushner and Sterk, 2005; Portes, 
1998). Neighborhoods with high levels of informal social control may enforce local norms on residents, however these norms may or may not be health promoting. Moreover, residents of cohesive neighborhoods may have more contact with one another, providing more opportunities for transmission of norms that, again, may enhance health or may be detrimental.

One health behavior of considerable interest in the context of this discussion is smoking, considered the leading behavioral cause of mortality, contributing to approximately $20 \%$ of deaths in the United States by some calculations (Mokdad et al., 2004). In addition to being a strong contributor to morbidity and mortality, smoking is strongly socially shaped and thus may be influenced by both the cohesiveness and the norms of communities. While the prevalence of smoking has been declining overall in the United States, $22 \%$ of adults are still current smokers (Trosclair et al., 2005); young people continue to take up smoking and currently approximately $25 \%$ of young people are smokers by the time they finish high school (Johnston et al., 2006). Broad national and statewide norm-changing media campaigns, smoking restriction legislation, and tobacco taxation that have attempted to change the social and structural environment of smoking are credited with contributing to the smoking declines to date; however, these declines have not been experienced equally in all populations, and there remains substantial variation in smoking geographically (Gilpin et al., 2004; Jiles et al., 2005; Nelson et al., 2001; Pierce et al., 1998). The local variation in smoking raises the question of what neighborhood social and structural characteristics might shape smoking behavior.

There is substantial research suggesting that neighborhood socioeconomic indicators are associated with smoking, however there is little research on other social and structural aspects of neighborhoods that may be related to smoking (Chuang et al., 2005a; Cubbin et al., 2006; Datta et al., 2006; Davey Smith et al., 1998; Diez Roux et al., 1997; Duncan et al., 1999; Ecob and Macintyre, 2000; Kleinschmidt et al., 1995; Monden et al., 2006; Ohlander et al., 2006; Reijneveld, 1998, 2002; Ross, 2000; Sundquist et al., 1999; Tseng et al., 2001; van Lenthe and Mackenback, 2006). There have been two studies examining neighborhood cohesion and control in association with smoking, and both found that more cohesive neighborhoods had lower prevalences of smoking (Miles, 2006; Patterson et al., 2004). There are no studies of neighborhood smoking norms and smoking among adults. Most of the research on substance use norms has been conducted in adolescents, and the norms have not typically been conceptualized as neighborhood level properties. The existing studies among adolescents show the importance of adult and peer norms for predicting smoking (Chuang et al., 2005b; Eisenberg and Forster, 2003; Ellickson et al., 2003; Ennett et al., 1997; Frohlich et al., 2002), suggesting these may be important social properties to consider in the context of adult smoking.

The potential importance of neighborhood collective efficacy and substance use norms in shaping smoking behavior is clear. However, the only extant research on the convergence of collective efficacy and smoking norms comes from one qualitative study conducted in Scotland (Stead et al., 2001). In the neighborhood studied, smoking was used to cope with a variety of stressors including unemployment and unsafe environments. In addition, there were strong pro-smoking norms in the neighborhood and a strong sense of local identification and cohesiveness. The cohesiveness and norms seemed to combine, such that “...these positive aspects of life [such as cohesiveness] may ironically be as bound up with and reinforcing of smoking as the more negative aspects of life [such as stressors]" (Stead et al., 2001).

In this analysis, we examined the relations of neighborhood collective efficacy and neighborhood smoking norms with smok- ing behavior, both separately and in combination. Building on the extant literature, we hypothesized that the association between collective efficacy and smoking would to be modified by the norms of the community, and specifically that the association would be reversed; cohesive neighborhoods with permissive smoking norms would have the highest smoking, and cohesive neighborhoods with strong anti-smoking norms would have the lowest smoking. Moreover, in this analysis we applied methods that address the problems of stratification and social selection which are challenges to interpreting neighborhood research (Oakes, 2004). In this analysis, we examine large neighborhood areas in New York City (NYC). While these areas are larger than neighborhoods examined in many studies (Sampson et al., 1997), it is interesting to examine whether these processes operate at a larger scale.

\section{Methods}

The New York Social Environment Study (NYSES) is a multilevel study designed to examine neighborhood level exposures, including economic, social and structural characteristics, and substance use in NYC. The NYSES was conducted between June and December of 2005. We used random-digit-dial methods to contact and interview 4000 NYC residents. One adult 18 years or older was interviewed by telephone in each household; the respondent was the person who either most recently or would next celebrate their birthday (randomly selected). Interviews were conducted in English or Spanish. The cooperation percentage was 54\%, representing the percentage of those contacted who agreed to participate in the study ((completed + screened out)/(completed + screened out + refused)). Respondents were offered $\$ 10$ in compensation for their participation. The study protocol was approved by the institutional review boards of the New York Academy of Medicine, the University of Michigan, and the University of California, Berkeley.

\subsection{Measures}

Respondents were interviewed with a structured questionnaire that included questions on demographic and socioeconomic characteristics including age, race and ethnicity, gender, marital status, place of birth, education, income, employment, years lived in the current neighborhood, and interview language. Smoking behavior was assessed using the World Mental Health Comprehensive International Diagnostic Interview (WMH-CIDI) tobacco module (Kessler and Ustun, 2004). Measures from this module that were used in the present analysis include current smoking and a retrospectively recalled history of smoking including age first tried smoking, age first smoked regularly, and age last smoked. Current smoking was the outcome in this analysis. Research suggests that self-report of smoking is highly concordant with bio-markers of smoking (Vartiainen et al., 2002), and that self-report assessments are comparable by phone and in-person (Nelson et al., 2003). History of smoking, in conjunction with number of years lived in the current neighborhood was used to assess smoking prior to residence in the current neighborhood. Respondents were classified as those who never tried smoking, those who tried smoking but never smoked regularly, and those who smoked weekly or daily prior to residence in the current neighborhood. Smoking prior to residence in the current neighborhood was controlled as a confounder in all analyses to account for one contributor to social selection (Diez Roux, 2004); by controlling for history of smoking we assure that associations observed are not due to the fact that smokers are likely to move to certain types of neighborhoods (Ahern et al., 2008b). Individual perception of smoking level in the neighborhood was assessed as the proportion of adults in the neighborhood perceived to be smokers (none, few, some, most, all), and was controlled to distinguish the effect that neighborhood norms might have on smoking from the effect of that observing smoking behaviors of others in the neighborhood might have on smoking. Individual perception of collective efficacy and smoking norms were adjusted to distinguish the effect of each neighborhood characteristic, from that of individual perception of that characteristic.

Respondents provided information about their residential address or nearest cross-streets so that their locations could be geocoded and linked to their neighborhoods of residence. ${ }^{1}$ The larger neighborhood areas for this analysis were the 59 community districts in NYC (median population 128,313 , median square miles

\footnotetext{
1 Of the 4000 respondents, 93.1\% (3725) were geocoded using address (2859) or nearest cross-streets (866). For the remaining 275 we had insufficient address or cross-street information, or only had zip code information. These participants were linked to the neighborhood that had the largest percentage of overlap with their zip code $(98.5 \%$ had more than $50 \%$ overlap between the zip code and the neighborhood, $68.7 \%$ had more than $75 \%$ overlap). An indicator for linkage to the neighborhood by zip code instead of by geocoding was considered in all analyses as a potential confounder.
} 
3), well-defined units, each headed by an administrative community board that, as such, has political and social relevance for the residents. Politically, the board of each community district serves as an advisory body with a formal role designated by the City Charter in matters including land use, determining local budget priorities and monitoring city service delivery. Meetings are held monthly and are open to the public. Each board establishes committees to focus on specific issues of concern. Socially, community districts were initially defined by a resident consultative process organized by the Office of City Planning to reflect residents' own descriptions of neighborhoods in the 1970s and as a consequence represent recognizable neighborhood areas with which residents identify, such as the Upper East Side, or the South Bronx. Many attributes of these neighborhood areas have been associated with resident health and health behaviors (Ahern and Galea, 2006; Ahern et al., 2008a,b; Bernstein et al., 2007; Galea et al., 2007, 2005, 2003; Hembree et al., 2005; Nandi et al., 2006).

Neighborhood collective efficacy was measured using the scale developed by Sampson and colleagues, which is comprised of the subscales of social cohesion and informal social control (Sampson et al., 1997). The social cohesion subscale includes five items with Likert responses and assesses residents' perceptions of the extent to which their neighbors are close-knit, are helpful, get along, share values, and are trustworthy. The informal social control subscale also includes five items with Likert responses and measures perceptions of the likelihood that neighbors would intervene if children skipped school, sprayed graffiti, or disrespected an adult, if there were a fight, or if the city were closing a firehouse. The responses of all residents in each neighborhood are averaged to calculate the neighborhood level measure of collective efficacy. Cronbach's alpha for the full collective efficacy scale was 0.77 (alpha for social cohesion was 0.64 , alpha for informal social control was 0.72), consistent with previous reports (Echeverria et al., 2004; Sampson et al., 1997).

Neighborhood smoking norms were measured using a question modified from the National Survey on Drug Use and Health (NSDUH). Respondents were asked their opinion of adults smoking cigarettes regularly and were given the options of "acceptable", "unacceptable" and “don't care". The neighborhood measure is the proportion of residents who believe it is "unacceptable" for adults to smoke cigarettes regularly in each neighborhood.

\subsection{Analysis}

All analyses were weighted by the ratio of the persons in the household to phone lines in the household to account for the probability of selection for interview. In addition, all analyses were replicated with additional weighting to adjust the respondents to the joint age, race/ethnicity, and gender distribution within each neighborhood as determined from the 2000 Census data. This was done to assess the potential impact of non-response of particular population groups, and to examine whether non-response was a plausible explanation for the analysis findings. Because neither the magnitude nor the statistical significance of any of the parameter estimates changed appreciably after this additional weighting, analyses with only the selection probability weights are presented here.

Several descriptive analyses were conducted initially. Neighborhood collective efficacy and neighborhood smoking norms were assessed descriptively to examine the range of each exposure and to identify potential outliers, and the correlation between the neighborhood characteristics was assessed to assure that the two measures were not too collinear to consider in combination. To assess the extent of stratification, we examined the probabilities or propensities for living in neighborhoods with (1) high versus low collective efficacy (median split), (2) high versus low smoking norms (median split), and (3) four category combinations of high and low neighborhood collective efficacy and smoking norms, modeled as a function of individual characteristics (history of smoking, individual smoking norm, age, race/ethnicity, gender, marital status, place of birth, education, income, employment, years lived in the neighborhood, and survey language) (Rosenbaum and Rubin, 1983). Through this process we were able to examine whether there was overlap between the "types" of people, defined by covariate combinations, who lived in low collective efficacy neighborhoods and those who lived in high collective efficacy neighborhoods. Propensities are often used as part of matched analysis as a tool to control confounding (Rosenbaum and Rubin, 1983), however they can also serve a useful purpose in describing the distribution of covariates across different exposure groups. If the people who actually lived in high and low collective efficacy neighborhoods had similar and predominantly overlapping distributions of propensities then we knew that there was little stratification in terms of the variables in the propensity model. This implied that people of all "types" lived in both high and low collective efficacy neighborhoods and that the analysis did not rely on extrapolation (e.g., if all Latina women older than 65 years lived in high collective efficacy neighborhoods, extrapolation would be required to assess the effect of low collective efficacy on this "type" of person).

The two neighborhood measures and their combination were examined in association with current smoking in bivariable analysis. Individual demographic and socioeconomic characteristics that were conceptually considered confounders based on the literature were considered as confounders in the multivariable analysis. In addition, age, race and ethnicity and gender were considered potential effect modifiers based on previous research on neighborhood characteristics (Robert, 1999); years lived in the neighborhood and history of smoking were also considered as they were logical potential effect modifiers that had not been examined in previous analyses. Missingness indicator variables were included for all covariates where some respondents declined to answer. Generalized estimating equation (GEE) logistic regression models were used in all analyses to account for potential clustering by neighborhood, and to estimate population averaged parameter estimates with robust standard errors (Zeger et al., 1988); each neighborhood exposure was examined separately in association with current smoking, then adjusted for demographic and socioeconomic confounders as well as history of smoking, and lastly adjusted for individual perception of smoking in the neighborhood and perception of each neighborhood characteristic (collective efficacy, smoking norms). All odds ratios presented are for a two standard deviation change in the neighborhood exposure. Finally, the combination of the neighborhood exposures was examined with an interaction term.

\section{Results}

The survey respondents were demographically similar to the overall population of NYC based on the most recent census, with 38.1\% White, 27.0\% African American, 5.0\% Asian, 27.2\% Hispanic, and $2.5 \%$ of other racial ethnic groups. Mean age was 45 years (range $18-94$ ), $51.1 \%$ of respondents were female, and $39.2 \%$ were born outside the United States. Approximately $20 \%$ of respondents were current smokers. A full description of the sample is provided in Table 1 .

Examination of neighborhood collective efficacy suggested there were no outliers; the mean collective efficacy value was 3.5 with a range of 2.7-4.0. A value of 4 indicates that on average respondents somewhat agree that the neighborhood is cohesive, while a value of 3 indicates that on average respondents neither agree nor disagree that the neighborhood is cohesive. Two neighborhoods were outliers in terms of their anti-smoking norms, with values more than two standard deviations below the mean. Because we were not comfortable making inference about neighborhoods with such low levels of anti-smoking norms based on only two outlying neighborhoods, these neighborhoods were excluded from the analyses of neighborhood smoking norms. For the included neighborhoods, the average proportion of residents who believed it was unacceptable to smoke was $60 \%$ with a range of $43-76 \%$. Neighborhood collective efficacy and smoking norms were weakly negatively correlated (Pearson correlation coefficient -0.25 , $p=0.06$ ).

Examining the propensities for living in neighborhoods with high versus low collective efficacy, high versus low anti-smoking norms, and four category combinations of collective efficacy and smoking norms, there was little suggestion of stratification. People of all "types", based on individual covariates, lived in neighborhoods with different values of the neighborhood exposures. In all instances, less than $1 \%$ of respondents had propensity values that were more extreme (higher or lower) than the propensity values among respondents living in neighborhoods with a different exposure (tables and plots of the propensity values are available from the corresponding author).

In the first set of GEE logistic regression models, presented in Table 2, we examined the relation between neighborhood collective efficacy and smoking alone, adjusting for confounders including smoking history, and adjusting for individual perception of smoking in the neighborhood and individual perception of collective efficacy. In all models, lower neighborhood collective efficacy was associated with slightly higher odds of smoking, but none of the associations were significant (fully adjusted OR 1.06 for a 2 standard deviation (S.D.) decrease in collective efficacy, 95\% CI 0.84-1.34). We found no interactions between collective efficacy and history of smoking, age, race/ethnicity, gender, or years lived in neighborhood.

In the second set of models, presented in Table 3, we examined the relation between neighborhood anti-smoking norms and smoking. In a bivariable GEE logistic regression model, more permissive 
Table 1

New York Social Environment Study respondent characteristics.

\begin{tabular}{|c|c|c|c|}
\hline & \multicolumn{2}{|c|}{ NYSES population } & \multirow{2}{*}{$\begin{array}{l}2000 \text { Census-NYC } \\
\%\end{array}$} \\
\hline & $N$ & $\%$ & \\
\hline Total & 4000 & 100.00 & 100.00 \\
\hline \multicolumn{4}{|l|}{ Age } \\
\hline $18-24$ & 350 & 11.78 & 13.23 \\
\hline $25-34$ & 685 & 18.05 & 22.54 \\
\hline $35-44$ & 815 & 19.50 & 20.82 \\
\hline $45-54$ & 808 & 21.42 & 16.68 \\
\hline $55-64$ & 612 & 14.85 & 11.26 \\
\hline$\geq 65$ & 690 & 14.39 & 15.46 \\
\hline \multicolumn{4}{|l|}{ Race/ethnicity } \\
\hline White & 1616 & 38.18 & 38.65 \\
\hline African American & 1055 & 27.03 & 22.97 \\
\hline Asian & 164 & 5.08 & 10.08 \\
\hline Hispanic & 958 & 27.19 & 24.71 \\
\hline Other & 95 & 2.52 & 3.59 \\
\hline \multicolumn{4}{|l|}{ Gender } \\
\hline Male & 1880 & 48.89 & 46.20 \\
\hline Female & 2120 & 51.11 & 53.80 \\
\hline \multicolumn{4}{|l|}{ Marital status } \\
\hline Married & 1632 & 47.33 & \\
\hline Divorced & 479 & 9.56 & \\
\hline Separated & 208 & 4.70 & \\
\hline Widowed & 354 & 6.68 & \\
\hline Never married & 1270 & 31.73 & \\
\hline \multicolumn{4}{|l|}{ Birth place } \\
\hline NYC & 1810 & 44.65 & \\
\hline Other US location & 731 & 16.13 & \\
\hline Different country & 1406 & 39.22 & \\
\hline \multicolumn{4}{|l|}{ Education } \\
\hline Less than high school & 508 & 13.89 & \\
\hline High school/GED & 923 & 24.69 & \\
\hline Some college & 879 & 23.23 & \\
\hline College graduate & 883 & 21.63 & \\
\hline Graduate work & 730 & 16.57 & \\
\hline \multicolumn{4}{|l|}{ Income } \\
\hline$\leq \$ 40,000$ & 1605 & 46.45 & \\
\hline$\$ 40,001-\$ 80,000$ & 1093 & 31.97 & \\
\hline$>\$ 80,000$ & 722 & 21.58 & \\
\hline \multicolumn{4}{|l|}{ Unemployed } \\
\hline Yes & 321 & 8.56 & \\
\hline No & 3658 & 91.43 & \\
\hline \multicolumn{4}{|c|}{ Smoking before moved to neighborhood } \\
\hline Ever smoked/tried smoking & 686 & 16.40 & \\
\hline Weekly/daily smoker & 1341 & 31.08 & \\
\hline Never smoked & 1973 & 52.52 & \\
\hline \multicolumn{4}{|l|}{ Current smoker } \\
\hline Yes & 835 & 20.40 & \\
\hline No & 3164 & 79.60 & \\
\hline
\end{tabular}

neighborhood smoking norms were significantly associated with more current smoking (OR 1.82 for a 2 S.D. increase in permissiveness of smoking norms, 95\% CI 1.48-2.24). After adjustment for demographic and socioeconomic confounders as well as smoking history, the association was somewhat attenuated (OR 1.67, 95\% CI 1.32-2.13). After further adjustment for individual perceptions of smoking in the neighborhood and individual smoking norms, the association between anti-smoking norms and current smoking was more attenuated but remained significant (OR 1.34, 95\% CI 1.03-1.74). When considering effect modification, we found interaction between history of smoking and anti-smoking norms (Table 3, model 4). Specifically, there was mainly an association between anti-smoking norms and current smoking among those with no previous history of smoking prior to residence in the current neighborhood (OR 2.88, 95\% CI 1.92-4.30).
In the final part of the analysis, we examined the interaction of neighborhood collective efficacy and neighborhood anti-smoking norms in association with smoking. As neighborhood anti-smoking norms were mainly associated with smoking among those with no history of smoking prior to residence in their current neighborhood, this analysis was initially conducted with the full population, and later considered in subgroups depending on smoking history. In the full population, there was some suggestion of the pattern hypothesized, however it was not statistically significant after adjustment for confounders. However in the subgroup with no history of smoking, the pattern was strong and consistent with the hypothesis. Among those with no prior history of smoking, the association between collective efficacy and smoking depended on the levels of anti-smoking norms in the neighborhood in fully adjusted models. As shown in Fig. 1, in neighborhoods with permissive smoking norms, higher collective efficacy was associated with more smoking. In contrast, in neighborhoods with strong anti-smoking norms, higher collective efficacy was associated with less smoking. The association between collective efficacy and smoking was modified by the smoking norms in the neighborhood.

\section{Discussion}

Using data from a representative survey of New York City residents, we found a combined association of neighborhood collective efficacy and smoking norms with smoking-where norms were permissive about smoking, higher collective efficacy strengthened this association and individual odds of smoking were the highest; where norms were strongly anti-smoking, higher collective efficacy was protective and individual odds of smoking were the lowest. This relation was strongest among those with no prior history of smoking. These findings corroborate qualitative research on this topic (Stead et al., 2001), and support discussions of the importance of considering norms around behavior in conjunction with community cohesion and social control (Portes, 1998).

In this analysis we adjusted for individual demographic and socioeconomic characteristics, as well as individual perceptions of neighborhood collective efficacy and individual smoking norms. Considering smoking norms, this means that the norms of the community are associated with smoking, beyond an individual's norm or opinion about smoking. For example, someone might believe it is acceptable to smoke, but because there are strong attitudes against smoking in the community, they may be less likely to smoke themselves. It is also important to note that individual norms are naturally a pathway through which community norms might influence individual smoking behaviors, so the estimates of associations between neighborhood norms and smoking adjusting for individual norms are likely to be conservative.

These findings suggest that efforts aimed at building collective efficacy as a way to improve health may also need to consider and target other characteristics of communities to accomplish the intended goal. In this instance, building collective efficacy without considering or addressing the norms about smoking might have the opposite of the intended effect if norms about smoking are permissive (Stead et al., 2001). A more complete assessment of the social environment may give us greater understanding of the range of issues that need to be considered in understanding the influences on behavior and in planning any sort of intervention. Of course, an association observed between existing community exposures and outcomes does not necessarily represent how a community might respond to an intervention on an exposure-this is one of the greatest challenges in the interpretation of community level research (Oakes, 2004; Sampson, 2003). However, this research has the potential to give insight into the types of community level factors that would be important to consider in intervention planning. 
Table 2

Generalized estimating equation logistic regression models of neighborhood collective efficacy and smoking.

\begin{tabular}{|c|c|c|c|c|c|c|c|c|c|c|c|c|}
\hline & \multicolumn{4}{|c|}{ Model 1} & \multicolumn{4}{|c|}{ Model $2^{\mathrm{a}}$} & \multicolumn{4}{|c|}{ Model $3^{a}$} \\
\hline & Beta & S.E. & OR & $95 \% \mathrm{CI}$ & Beta & S.E. & OR & $95 \% \mathrm{CI}$ & Beta & S.E. & OR & $95 \% \mathrm{CI}$ \\
\hline Neighborhood collective efficacy ${ }^{b}$ & 0.13 & 0.13 & 1.13 & $0.88-1.46$ & 0.13 & 0.12 & 1.14 & $0.90-1.43$ & 0.06 & 0.12 & 1.06 & $0.84-1.34$ \\
\hline \multicolumn{13}{|l|}{ Smoking before moved to neighborhood } \\
\hline Never smoked & & & & & & & 1.00 & & & & 1.00 & \\
\hline Ever smoked/tried smoking & & & & & 0.07 & 0.18 & 1.08 & $0.75-1.54$ & 0.06 & 0.18 & 1.06 & $0.74-1.52$ \\
\hline Weekly/daily smoker & & & & & 2.83 & 0.15 & 16.97 & $12.73-22.62$ & 2.81 & 0.15 & 16.57 & $12.43-22.09$ \\
\hline \multicolumn{13}{|c|}{ Individual perception of smoking in neighborhood } \\
\hline No adults smoke & & & & & & & & & & & 1.00 & \\
\hline Few adults smoke & & & & & & & & & 1.29 & 0.65 & 3.64 & $1.03-12.88$ \\
\hline Some adults smoke & & & & & & & & & 1.55 & 0.65 & 4.73 & $1.32-16.99$ \\
\hline Most adults smoke & & & & & & & & & 1.85 & 0.68 & 6.34 & $1.68-23.87$ \\
\hline All adults smoke & & & & & & & & & 1.69 & 0.72 & 5.43 & $1.31-22.40$ \\
\hline Don’t know & & & & & & & & & 1.51 & 0.66 & 4.54 & $1.25-16.51$ \\
\hline Individual collective efficacy perception & & & & & & & & & 0.04 & 0.07 & 1.04 & $0.91-1.19$ \\
\hline
\end{tabular}

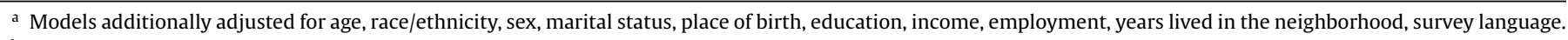

b Betas and ORs for a 2 standard deviation decrease in neighborhood collective efficacy.

In addition, aspects of the structural environment such as availability of cigarettes, pricing and taxation of cigarettes, and advertising would likely be important to consider in conjunction with aspects of the social environment examined here.

It is also notable that the associations between neighborhood norms, collective efficacy and smoking were strongest among those who did not have any history of smoking prior to living in the current neighborhood. Those with no prior history of smoking comprise more than half of respondents, so at the population level this represents a substantial group affected. Within this group, $10 \%$ started smoking since living in their current neighborhood. The observation that neighborhood norms and collective efficacy were strongly related to smoking for those with no prior history of smoking suggests that these may be important factors in smoking initiation. However, the absence of associations shown between neighborhood smoking norms and smoking does not mean that norms do not matter at all for those with a history of smoking. It may be particularly interesting to consider norms in relation to quitting for those with a smoking history.

This analysis raises the issue of the scale(s) at which the process of collective efficacy operates, as earlier analyses have typically considered neighborhoods smaller than those in this analysis (Sampson et al., 1997). The large neighborhood areas used in our analysis are consistent with what most of our respondents reported thinking of as their neighborhoods, residential density is high in NYC, and New Yorkers walk long distances as part of daily life, all suggesting our large neighborhood areas are relevant neighborhoods for residents. In addition, seminal work on collective efficacy and related constructs did not conceptualize them as relevant to one specific size of place, and the construct has been considered in units widely varied in size including countries, counties and neighborhoods (Bandura, 2001; Durkheim, 1897; Faris and Dunham, 1939; Sampson et al., 1997; Shaw and McKay, 1942). However, measuring the constructs of collective efficacy and smoking norms at this larger neighborhood level certainly may smooth over heterogeneity in these measures that could have been observed at a smaller level of resolution. Overall, examining these and other constructs at different scales is informative as to the scales and ways in which they may operate on health and health behavior, given that the processes operating in a small neighborhood may be different from those in a large neighborhood area.

It will be interesting for future work to examine whether these results are replicated in other cultural settings. This analysis was inspired by qualitative work in Scotland (Stead et al., 2001), and our results were consistent with those findings suggesting the phenomenon is not unique to the United States context. However, it will also be interesting to consider the combined effects of norms and collective efficacy on substance use in settings in which the range of norms and collective efficacy might be quite different; for example, in places with very low collective efficacy the effect of group norms might be attenuated as limited interactions lead to limited exposure to the norms of others. Certainly research in a variety of countries demonstrating heterogeneous effects of measures of social capital and cohesion among cultural population subgroups suggests the potential for combined effects of measures of capital and cohesion with other cultural aspects in shaping health and health behavior (Baron-Epel et al., 2008; Kim and Kawachi, 2006; Pronyk et al., 2008).

There are several limitations to this study. The cooperation percentage was $54 \%$, which is consistent with many other recent telephone-based studies (Galea and Tracy, 2007). However, this cooperation percentage does raise concern about how well the study sample represents the city of New York. Participants were informed that they would be participating in a "survey about the neighborhoods where New Yorkers live and what people think about their neighborhoods", and thus they were not likely to refuse based on their use or non-use of cigarettes. The distribution of demographic characteristics such as age, race, gender and birth place is very similar to the 2000 Census data for NYC. Moreover the findings were robust to additional weighting to adjust the respondents to the age, race/ethnicity, and gender distribution within each neighborhood as determined from the 2000 Census data, suggesting non-response did not distort the study findings. However the participants may still differ from those in the city overall in ways that we were unable to capture. The data on smoking behaviors in this study were self-reported, and while self-report is standard practice in substance use research, there may be differences between actual behaviors and reported behaviors. The neighborhood smoking norm variable was based on a question originally designed to assess individual norms, and thus represents only one of many ways these norms could have been assessed. The issue of contagion has been raised in recent discussions of analyses that examine community characteristics and individual outcomes (Oakes, 2004). Essentially, this problem arises when the prevalence of the outcome (in this case smoking) affects the probability of the outcome for any individual (i.e., prevalence affects incidence). This dependence of the outcomes between individu- 
Table 3

Generalized estimating equation logistic regression models of neighborhood smoking norms and smoking.

\begin{tabular}{|c|c|c|c|c|c|c|c|c|c|c|c|c|c|c|c|c|}
\hline & \multicolumn{4}{|c|}{ Model 1} & \multicolumn{4}{|c|}{ Model $2^{\mathrm{a}}$} & \multicolumn{4}{|c|}{ Model 3a } & \multicolumn{4}{|c|}{ Model $4^{\mathrm{a}, \mathrm{b}}$} \\
\hline & Beta & S.E. & OR & $95 \% \mathrm{CI}$ & Beta & S.E. & OR & $95 \% \mathrm{CI}$ & Beta & S.E. & OR & $95 \% \mathrm{CI}$ & Beta & S.E. & OR & $95 \% \mathrm{CI}$ \\
\hline Neighborhood smoking norms ${ }^{c}$ & 0.60 & 0.11 & 1.82 & $1.48-2.24$ & 0.51 & 0.12 & 1.67 & $1.32-2.12$ & 0.29 & 0.13 & 1.34 & $1.03-1.74$ & 1.06 & 0.21 & 2.88 & $1.92-4.3$ \\
\hline \multicolumn{17}{|l|}{ Smoking before moved to neighborhood } \\
\hline Ever smoked/tried smoking & & & & & -0.04 & 0.17 & 0.96 & $0.69-1.34$ & -0.14 & 0.19 & 0.87 & $0.60-1.25$ & -0.11 & 0.18 & 0.90 & $0.63-1.28$ \\
\hline Weekly/daily smoker & & & & & 2.82 & 0.15 & 16.82 & $12.51-22.62$ & 2.70 & 0.16 & 14.90 & $10.99-20.20$ & 2.72 & 0.15 & 15.21 & $11.33-20.41$ \\
\hline \multicolumn{17}{|l|}{ Individual perception of smoking in neighborhood } \\
\hline No adults smoke & & & & & & & & & & & 1.00 & & & & 1.00 & \\
\hline Few adults smoke & & & & & & & & & 1.43 & 0.65 & 4.17 & $1.17-14.87$ & 1.39 & 0.66 & 4.00 & $1.09-14.65$ \\
\hline Some adults smoke & & & & & & & & & 1.60 & 0.66 & 4.96 & $1.36-18.02$ & 1.57 & 0.67 & 4.82 & $1.29-18.08$ \\
\hline Most adults smoke & & & & & & & & & 1.91 & 0.70 & 6.73 & $1.72-26.35$ & 1.88 & 0.72 & 6.52 & $1.60-26.52$ \\
\hline All adults smoke & & & & & & & & & 1.92 & 0.75 & 6.80 & $1.57-29.49$ & 1.89 & 0.77 & 6.65 & $1.48-29.8$ \\
\hline Don’t know & & & & & & & & & 1.28 & 0.66 & 3.59 & $0.98-13.15$ & 1.24 & 0.67 & 3.46 & $0.92-12.97$ \\
\hline \multicolumn{17}{|l|}{ Individual smoking norm } \\
\hline No opinion & & & & & & & & & & & 1.00 & & & & 1.00 & \\
\hline Acceptable & & & & & & & & & 0.48 & 0.16 & 1.62 & $1.19-2.19$ & 0.46 & 0.16 & 1.59 & $1.16-2.18$ \\
\hline Unacceptable & & & & & & & & & -1.47 & 0.12 & 0.23 & $0.18-0.29$ & -1.47 & 0.12 & 0.23 & $0.18-0.29$ \\
\hline Missing & & & & & & & & & 0.01 & 0.30 & 1.01 & $0.56-1.81$ & 0.04 & 0.29 & 1.04 & $0.59-1.84$ \\
\hline \multicolumn{17}{|l|}{ Smoking history $\times$ smoking norms } \\
\hline Never smoked $\times$ smoking norms & & & & & & & & & & & & & & & & \\
\hline Ever smoked/tried smoking $\times$ smoking norms & & & & & & & & & & & & & -1.23 & 0.42 & - & \\
\hline Weekly/daily smoker $\times$ smoking norms & & & & & & & & & & & & & -1.18 & 0.27 & - & \\
\hline
\end{tabular}

a Models additionally adjusted for age, race/ethnicity, sex, marital status, place of birth, education, income, employment, years lived in the neighborhood, and survey language.

b ORs are not presented for some betas in model 4 because they must be interpreted with the interaction. The OR for the association between neighborhood smoking norms and smoking among those who never smoked

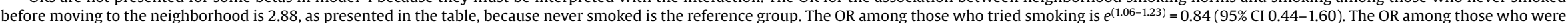
weekly or daily smokers is $e^{(1.06-1.18)}=0.89(95 \% \mathrm{Cl} 0.62-1.26)$.

c Betas and ORs for a 2 standard deviation decrease in neighborhood anti-smoking norms (increase in permissiveness of smoking norms). 


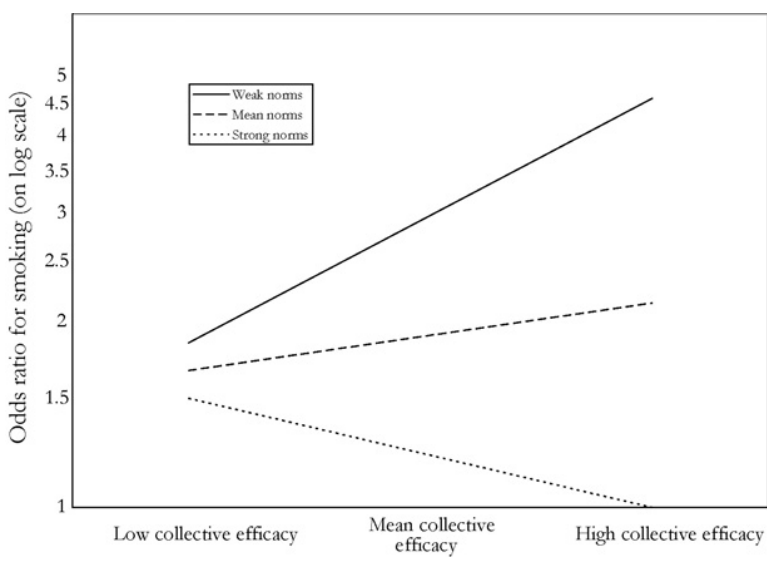

Fig. 1. Odds ratios for the association between neighborhood collective efficacy and smoking, at different levels of neighborhood smoking norms, for the group with no history of smoking prior to living in the current neighborhood (interaction $p$ value $<0.001$ )

Neighborhoods with low collective efficacy are 1 S.D. below the mean, indicating they have less social cohesion and informal social control. Neighborhoods with high collective efficacy are 1 S.D. above the mean, indicating they have more social cohesion and informal social control. Neighborhoods with weak norms are 1 S.D. below the mean of the percentage who believe it is unacceptable for adults to smoke regularly, meaning norms are more permissive around smoking. Neighborhoods with strong norms are 1 S.D. above the mean of the percentage who believe it is unacceptable for adults to smoke regularly, meaning norms are more anti-smoking.

als means that parameter estimates from a traditional analysis do not accurately reflect how much of a change in outcome would be expected from a change in exposure (Koopman and Longini, 1994). A complementary analytic approach that merits consideration for future analyses of neighborhood characteristics and health would be one that can account for these dynamic processes, such as the systems modeling approaches that have been used to model infectious diseases (Koopman and Longini, 1994; Ness et al., 2007).

Among several strengths, this study includes a large populationbased sample. We assessed the extent of stratification using propensities and found that there was virtually no stratification in this analysis. We also accounted for one contributor to social selection by adjusting for history of smoking prior to each person's residence in their current neighborhood. Social selection has been considered one of the major barriers to determining whether the environment has an influence on people, or whether people who have worse health "drift" or select into worse types of environments (Oakes, 2004; Sampson, 2003). Because we adjusted for history of smoking, associations observed are not due to an effect of smokers moving into certain types of neighborhoods (e.g., neighborhoods with permissive smoking norms). In addition, we adjusted for individual perception of smoking in the neighborhood, assuring that any association with neighborhood smoking norms is not explained by residents observing more smoking behavior in certain neighborhoods.

Overall, we found that two aspects of the social environment, collective efficacy and smoking norms, were associated with current smoking, and that these two elements of the environment had to be considered together to fully understand their relation with smoking behavior. This and other analyses that consider the complexities of neighborhoods, such as the combinations of characteristics that may shape their effects, may ultimately give us a richer understanding of how the social and structural aspects of the environment shape health and health behavior.

\section{Conflict of interest}

All authors declare that they have no conflicts of interest.

\section{Acknowledgements}

We would like to thank Dr. Lorraine Midanik for her comments on an earlier draft of this paper.

Role of funding source: Financial support for this research was provided by the grant DA 017642 from the National Institute on Drug Abuse (NIDA). The NIDA had no further role in study design; in the collection, analysis and interpretation of data; in the writing of the report; or in the decision to submit the paper for publication.

Contributors: Dr. Ahern collaborated on the design and implementation of the study, designed and implemented the analysis, conducted the literature review, and wrote the manuscript. Dr. Galea obtained study funding, collaborated on the design and implementation of the study, and substantially edited all sections of the manuscript. Dr. Hubbard provided statistical guidance for the analysis plan and helped write the statistical parts of Sections $2-4$. Dr. Syme collaborated on the conceptualization of the paper and provided substantial editing to the manuscript. All authors contributed to and have approved the final manuscript.

\section{References}

Ahern, J., Galea, S., 2006. Social context and depression after a disaster: the role of income inequality. J. Epidemiol. Community Health 60, 766-770.

Ahern, J., Galea, S., Hubbard, A., Karpati, A., 2008a. Population vulnerabilities and capacities related to health: a test of a model. Soc. Sci. Med. 66, 691-703.

Ahern, J., Galea, S., Hubbard, A., Midanik, L., Syme, S.L., 2008b. “Culture of drinking” and individual problems with alcohol use. Am. J. Epidemiol. 167, 1041-1049.

Bandura, A., 2001. Social cognitive theory: an agentic perspective. Annu. Rev. Psychol. $52,1-26$.

Baron-Epel, O., Weinstein, R., Haviv-Mesika, A., Garty-Sandalon, N., Green, M.S 2008. Individual-level analysis of social capital and health: a comparison of Arab and Jewish Israelis. Soc. Sci. Med. 66, 900-910.

Bernstein, K.T., Galea, S., Ahern, J., Tracy, M., Vlahov, D., 2007. The built environment and alcohol consumption in urban neighborhoods. Drug Alcohol Depend. 91, 244-252.

Chuang, Y.-C., Cubbin, C., Ahn, D., Winkleby, M.A., 2005a. Effects of neighbourhood socioeconomic status and convenience store concentration on individual level smoking. J. Epidemiol. Community Health, 59.

Chuang, Y.-C., Ennett, S.T., Bauman, K.E., Foshee, V.A., 2005b. Neighborhood influences on adolescent cigarette and alcohol use: mediating effects through parent and peer behaviors. J. Health Soc. Behav. 46, 187-204.

Cubbin, C., Sundquist, K., Ahlen, H., Johansson, S.-E., Winkleby, M.A., Sundquist, J., 2006. Neighborhood deprivation and cardiovascular disease risk factors: protective and harmful effects. Scand. J. Public Health 34, 228-237.

Datta, G.D., Subramanian, S., Colditz, G.A., Kawachi, I., Palmer, J.R., Rosenberg, L. 2006. Individual, neighborhood, and state-level predictors of smoking among US Black women: a multilevel analysis. Soc. Sci. Med. 63, 1034-1044.

Davey Smith, G., Hart, C., Watt, G., Hole, D., Hawthorne, V., 1998. Individual social class, area-based deprivation, cardiovascular disease risk factors, and mortality: the Renfrew and Paisley study. J. Epidemiol. Community Health 52, 399-405.

Diez Roux, A.V., 2004. Estimating neighborhood health effects: the challenges of causal inference in a complex world. Soc. Sci. Med. 58, 1953-1960.

Diez Roux, A.V., Nieto, F.J., Mutaner, C., Tyroler, H.A., Comstock, G.W., Shahar, E., Cooper, L.S., Watson, R.L., Szklo, M., 1997. Neighborhood environments and coronary heart disease: a multilevel analysis. Am. J. Epidemiol. 146, 48-63.

Duncan, C., Jones, K., Moon, G., 1999. Smoking and deprivation: are there neighbourhood effects? Soc. Sci. Med. 48, 497-505.

Durkheim, E., 1897. Suicide: A Study in Sociology. Free Press, New York.

Echeverria, S.E., Diez-Roux, A.V., Link, B.G., 2004. Reliability of self-reported neighborhood characteristics. J. Urban Health 81, 682-701.

Ecob, R., Macintyre, S., 2000. Small area variations in health related behaviours; do these depend on the behavior itself, its measurement, or on personal characteristics. Health Place 6, 261-274.

Eisenberg, M.E., Forster, J.L., 2003. Adolescent smoking behaviour. Measures of social norms. Am. J. Prev. Med. 25, 122-128.

Ellickson, P.L., Bird, C.E., Orlando, M., Klein, D.J., McCaffrey, D.F., 2003. Socia context and adolescent health behavior: does school-level smoking prevalence affect students' subsequent smoking behavior? J. Health Soc. Behav. 44, 525-535.

Ennett, S.T., Flewelling, R.L., Lindrooth, R.C., Norton, E.C., 1997. School and neighborhood characteristics associated with school rates of alcohol, cigarette, and marijuana use. J. Health Soc. Behav. 38, 55-71. 
Faris, R.E., Dunham, W., 1939. Mental Disorders in Urban Areas: An Ecological Study of Schizophrenia and Other Psychoses. University of Chicago Press, Chicago.

Frohlich, K.L., Potvin, L., Gauvin, L., Chabot, P., 2002. Youth smoking initiation: disentangling context from composition. Health Place 8, 155-166.

Galea, S., Ahern, J., Nandi, A., Tracy, M., Beard, J., Vlahov, D., 2007. Urban neighborhood poverty and the incidence of depression in a population-based cohort study. Ann. Epidemiol. 17, 171-179.

Galea, S., Ahern, J., Rudenstine, S., Wallace, Z., Vlahov, D., 2005. Urban built environment and depression: a multilevel analysis. J. Epidemiol. Community Health 59, 822-827.

Galea, S., Ahern, J., Vlahov, D., Coffin, P.O., Fuller, C., Leon, A.C., Tardiff, K., 2003. Income distribution and risk of fatal drug overdose in New York City neighborhoods. Drug Alcohol Depend. 70, 139-148.

Galea, S., Tracy, M., 2007. Participation rates in epidemiologic studies. Ann. Epidemiol. 17, 643-653.

Gilpin, E.A., Lee, L., Pierce, J.P., 2004. Changes in population attitudes about where smoking should not be allowed: California versus the rest of the USA. Tob. Control $13,38-44$.

Greiner, K.A., Li, C., Kawachi, I., Hunt, D.C., Ahluwalia, J.S., 2004. The relationships of social participation and community ratings to health and health behaviors in areas with high and low population density. Soc. Sci. Med., 59.

Hembree, C. Galea, S., Ahern, J., Tracy, M. Markham Piper, T, Miller, J., Vlahov, D. Tardiff, K.J., 2005. The urban built environment and overdose mortality in New York City neighborhoods. Health Place 11, 147-156.

Jiles, R., Hughes, E., Murphy, W., Flowers, N., McCracken, M., Roberts, H., Ochner, M. Balluz, L., Mokdad, A., Elam-Evans, L., Giles, W., 2005. Surveillance for certain health behaviors among states and selected local areas-Behavioral Risk Factor Surveillance System, United States, 2003. MMWR Surveill. Summ. 54, 1-116.

Johnston, L.D., O'Malley, P.M., Bachman, J.G., Schulenberg. J.E., 2006. Monitoring the future, national survey results on drug use 1975-2005. Natl. Inst. Drug Abuse II.

Kawachi, I., Berkman, L., 2000. Social cohesion, social capital, and health. In: Berkman, L., Kawachi, I. (Eds.), Social Epidemiology. Oxford University Press, New York, pp. 174-190.

Kessler, R.C., Ustun, T.B., 2004. The World Mental Health (WMH) survey initiative version of the World Health Organization (WHO) Composite International Diag nostic Interview (CIDI). Int. J. Methods Psychiatr. Res. 13, 93-121.

Kim, D., Kawachi, I., 2006. A multilevel analysis of key forms of community- and individual-level social capital as predictors of self-rated health in the United States. J. Urban Health 83, 813-826.

Kleinschmidt, I., Hills, M., Elliott, P., 1995. Smoking behaviour can be predicted by neighbourhood deprivation measures. J. Epidemiol. Community Health 49, S72-77.

Koopman, J., Longini, I., 1994. The ecological effect of individual exposures and nonlinear disease dynamics in populations. Am. J. Public Health 84, 836-842.

Kushner, H.I., Sterk, C.E., 2005. The limits of social capital: Durkheim, suicide, and social cohesion. Am. J. Public Health 95, 1139-1143.

Lomas, J., 1998. Social capital and health: implications for public health and epidemiology. Soc. Sci. Med. 47, 1181-1188.

Miles, R., 2006. Neighborhood disorder and smoking: findings of a European urban survey. Soc. Sci. Med. 63, 2464-2475.

Mokdad, A.H., Marks, J., Stroup, D., Gerberding, J., 2004. Actual causes of death in the United States, 2000. JAMA 291, 1238-1245.

Monden, C.W., van Lenthe, F.J., Mackenback, J.P., 2006. A simultaneous analysis of neighbourhood and childhood socio-economic environment with self-assessed health and health-related behaviours. Health Place 12, 394-403.

Nandi, A., Galea, S., Ahern, J., Bucciarelli, A., Vlahov, D., Tardiff, K., 2006. What explains the association between neighborhood-level income inequality and the risk of fatal overdose in New York City? Soc. Sci. Med. 63, 662-674.

Nelson, D., Marcus, S., Wells, H., Laird, G., Dever, J., 2001. Cigarette smoking in 99 metropolitan areas-United States 2000. MMWR 50, 1107-1113.
Nelson, D.E., Powell-Griner, E., Town, M., Kovar, M.G., 2003. A comparison of national estimates from the National Health Interview Survey and the Behavioral Risk Factor Surveillance System. Am. J. Public Health 93, 1335-1341.

Ness, R.B., Koopman, J.S., Roberts, M.S., 2007. Causal system modeling in chronic disease epidemiology: a proposal. Ann. Epidemiol. 17, 564-568.

NSDUH, National Survey on Drug Use and Health. http://www.oas.samhsa. gov/nhsda.htm (accessed February 4, 2008).

Oakes, J.M., 2004. The (mis)estimation of neighborhood effects: causal inference for a practicable social epidemiology. Soc. Sci. Med. 58, 1929-1952.

Ohlander, E., Vikstrom, M., Lindstrom, M., Sundquist, K., 2006. Neighbourhood nonemployment and daily smoking: a population-based study of women and men in Sweden. Eur. J. Public Health 16, 78-84.

Patterson, J.M., Eberly, L.E., Ding, Y., Hargreaves, M., 2004. Associations of smoking prevalence with individual and area level social cohesion. J. Epidemiol. Community Health 58, 692-697.

Pierce, J.P., Gilpin, E.A., Emery, S.L., White, M.M., Rosbrook, B., Berry, C.C., Farkas, A.J., 1998. Has the California tobacco control program reduced smoking? JAMA 280, 893-899.

Portes, A., 1998. Social capital: its origins and applications in modern sociology. Annu. Rev. Sociol. 24, 1-24.

Pronyk, P.M., Harpham, T., Morison, L.A., Hargreaves, J.R., Kim, J.C., Phetla, G., Watts, C.H., Porter, J.D., 2008. Is social capital associated with HIV risk in rural South Africa? Soc. Sci. Med. 66, 1999-2010.

Reijneveld, S., 1998. The impact of individual and area characteristics on urban socioeconomic differences in health and smoking. Int. J. Epidemiol. 27, 33-40.

Reijneveld, S., 2002. Neighbourhood socioeconomic context and self reported health and smoking: a secondary analysis of data on seven cities. J. Epidemiol. Community Health 56, 935-942.

Robert, S.A., 1999. Socioeconomic position and health: the independent contribution of community to socioeconomic context. Annu. Rev. Sociol. 25, 489-516.

Rosenbaum, P.R., Rubin, D.B., 1983. The central role of the propensity score in observational studies for causal effects. Biometrika 70, 41-55.

Ross, C.E., 2000. Walking, exercising, and smoking: does neighborhood matter? Soc. Sci. Med. 51, 265-274

Sampson, R.J., 2003. Neighborhood-level context and health: lessons from sociology. In: Kawachi, I., Berkman, L.F. (Eds.), Neighborhoods and Health. Oxford University Press, Oxford, pp. 132-146.

Sampson, R.J., Raudenbush, S.W., Earls, F., 1997. Neighborhoods and violent crime: a multilevel study of collective efficacy. Science 277, 918-924.

Shaw, C.R., McKay, H.D., 1942. Juvenile Delinquency and Urban Areas. The University of Chicago Press, Chicago.

Stead, M., MacAskill, S., MacKintosh, A.-M., Reece, J., Eadie, D., 2001. "It's as if you're locked in": qualitative explanations for area effects on smoking in disadvantaged communities. Health Place 7, 333-343.

Sundquist, J., Malmstrom, M., Johansson, S.-E., 1999. Cardiovascular risk factors and the neighbourhood environment: a multilevel analysis. Int. J. Epidemiol. 28, $841-845$.

Trosclair, A., Caraballo, R., Marlarcher, A., Husten, C., Pechacek, T., 2005. Cigarette smoking among adults-United States, 2003. MMWR 54, 509-513.

Tseng, M., Yeatts, K., Millikan, R., Newman, B., 2001. Area-level characteristics and smoking in women. Am. J. Public Health 91, 1847-1850.

van Lenthe, F.J., Mackenback, J.P., 2006. Neighbourhood and individual socioeconomic inequalities in smoking: the role of physical neighbourhood stressors. J. Epidemiol. Community Health 60, 699-705.

Vartiainen, E., Seppala, T., Lillsunde, P., Puska, P., 2002. Validation of self reported smoking by serum cotinine measurement in a community-based study. J. Epidemiol. Community Health 56, 167-170.

Zeger, S.L., Liang, K.Y., Albert, P.S., 1988. Models for longitudinal data: a generalized estimating equation approach. Biometrics 44, 1049-1060. 